\title{
PERSPECTIVAS TEÓRICAS E METODOLÓGICAS PARA SE \\ PENSAR A IDENTIDADE TERRITORIAL CAMPONESA \\ NOS LIVROS DIDÁTICOS DE GEOGRAFIA
}

\author{
THEORETICAL AND METHODOLOGICAL PERSPECTIVES \\ FOR THINKING ABOUT PEASANT TERRITORIAL \\ IDENTITY IN GEOGRAPHY TEXTBOOKS
}

\section{PERSPECTIVAS TEÓRICAS Y METODOLÓGICAS PARA PENSAR LA IDENTIDAD TERRITORIAL CAMPESINA EN LOS MANUALES DE GEOGRAFÍA}

\author{
Francilane Eulália de Souza ${ }^{1}$ \\ Departamento de Geografia, Universidade \\ Estadual de Goiás (UEG) \\ Formosa, Goiás, Brasil \\ E-mail: francilanee@hotmail.com \\ Orcid:0000-0002-7610-8099
}

\begin{abstract}
Resumo: O Livro didático é um instrumento didático imbuído de paradigmas dominantes e, portanto, também constitui um espaço de disputa de poder. Nesse contexto, apresentamos análises teóricas e metodológicas sobre os conteúdos contidos na coleção de livros didáticos de Geografia Expedições Geográficas voltada para o ensino fundamental, observando se os mesmos permitem pensar o território em sua totalidade, abrindo possibilidades para valorizar a identidade territorial camponesa. Para tanto, partimos da pesquisa bibliográfica e a documental. Nessa investigação, consideramos que os volumes de livro didático aqui analisados, na medida em que sejam tomados de forma fiel pelos professores de Geografia em suas práxis, vêm concorrendo para uma não valorização da identidade territorial camponesa. Nesse contexto, as teorias da educação do campo podem ser de precioso auxílio, numa perspectiva de desconstrução e valorização de uma Geografia calcada em análises do campo como espaço das múltiplas dimensões da vida.
\end{abstract}

Palavras Chave: Livro didático. Identidade Territorial Camponesa. Geografia

\begin{abstract}
The didactic book is a didactic instrument imbued with dominant paradigms and, therefore, it also constitutes a space of power dispute. In this context, we present theoretical and methodological analyzes of the contents contained in the Geography Geographic Expeditions textbooks collection geared towards elementary education, observing whether
\end{abstract}

1 Profa. Dra. da Universidade Estadual de Goiás (UEG). 
they allow thinking of the territory in its entirety, opening up possibilities to enhance the peasant territorial identity. For this, we started from bibliographic and documentary research. In this investigation, we consider that the textbook volumes analyzed here, insofar as they are taken faithfully by Geography teachers in their praxis, have been contributing to a lack of appreciation of the peasant territorial identity. In this context, the theories of rural education can be of precious help, in a perspective of deconstruction and valorization of a Geography based on analyzes of the field as a space of the multiple dimensions of life.

Keywords: Textbook. Peasant Territorial Identity. Geography.

Resumen: El libro didáctico es un instrumento didáctico imbuido de paradigmas dominantes y, por tanto, también constituye un espacio de disputa de poder. En este contexto, presentamos análisis teóricos y metodológicos de los contenidos en la colección de libros de texto Geographic Expeditions Geographic orientados a la educación básica, observando si permiten pensar el territorio en su totalidad, abriendo posibilidades para potenciar la identidad territorial campesina. Para ello partimos de una investigación bibliográfica y documental. En esta investigación, consideramos que los volúmenes de libros de texto aquí analizados, en la medida en que son tomados fielmente por los docentes de Geografía en su praxis, han contribuido a una falta de apreciación de la identidad territorial campesina. En este contexto, las teorías de la educación rural pueden ser de valiosa ayuda, en una perspectiva de deconstrucción y valorización de una Geografía basada en análisis del campo como espacio de las múltiples dimensiones de la vida.

Palabras clave: Libro de texto. Identidad Territorial Campesina. Geografía.

Data de recebimento: 02/10/2020

Data de aprovação: 20/12/2020

\section{1 - INTRODUÇÃO}

O livro didático vem sendo tomado como um dos principais instrumentos de ensino nas escolas do ensino básico. Conforme Tonini (2011, p. 145), trata-se de "um dos recursos de aprendizagem mais universal de todos na cultura escolar". Podemos acrescentar ainda que, para muitos dos alunos camponeses, esse é o primeiro livro com que eles têm contato. Assim, considerando as dificuldades de acesso à informação desses sujeitos, seja pela ausência de computadores com acesso à internet ou até mesmo de recursos para adquirir material impresso, o livro didático utilizado no campo não é apenas um instrumento de ensino, mas frequentemente é o único material de estudo e de consulta do alunado camponês.

$\mathrm{Na}$ década de 1990 no Brasil, tomou impulso o movimento que defende a educação no/do campo, que, segundo Fernandes (2006, p.28), "nasceu das demandas dos movimentos camponeses na construção de uma política educacional para os assentamentos de reforma agrária”. Esse paradigma da Educação do Campo fornece subsídios para se pensar o livro didático voltado para o ensino básico de Geografia numa perspectiva de valorização da identidade territorial camponesa e, por conseguinte, do fortalecimento do território do camponês. 
É nesse contexto que apresentamos as análises da coleção de livros didáticos - manual do professor - intitulada Expedições Geográficas, voltada para o ensino fundamental II, cuja edição atual já está adequada à Base Nacional Comum Curricular (BNCC), tendo sido selecionada pelo PNLD e editada em 2018.

Essa coleção vem sendo adotada nas 19 escolas situadas no campo do município de Formosa. Este território, juntamente com o município de Cavalcante, possui o maior quantitativo de escolas do campo do estado de Goiás, o que, dentre outros elementos, nos motiva a refletir se o livro didático tem sido "tomado" enquanto instrumento de valorização da identidade territorial camponesa. Essas escolas adotam livros didáticos que são escolhidos pelos professores regentes, e que não necessariamente serão utilizados de modo a valorizar a identidade territorial camponesa. Esses e outros motivos levaram à execução do projeto de pesquisa intitulado "Os livros didáticos de geografia na valorização da identidade territorial camponesa" nos últimos anos.

Assim, neste artigo, apresentamos considerações teóricas e metodológicas sobre os elementos contidos na coleção de livros didáticos de Geografia Expedições Geográficas, voltada para o ensino fundamental, observando se a mesma permite pensar o território em sua totalidade, abrindo possibilidades para refletir sobre a identidade territorial camponesa e valorizá-la. Para tanto, tomamos a pesquisa bibliográfica e a documental como caminho primeiro para a execução da pesquisa, tendo a identidade territorial camponesa como uma de nossas categorias centrais de análise, alicerçada nas teorias da educação no/do campo. Nesse contexto, uma das principais contribuições deste trabalho é justamente colocar em pauta um dos princípios da educação do campo, isto é, que ela seja estruturada por instrumentos didáticos voltados para os anseios e para a vida no campo.

Vale ressaltar que, embora estejamos há mais de 15 anos realizando análise de livro didático de Geografia, seja em projetos de pesquisa, seja em tese de doutorado e em orientação de TCCs de graduação e pós-graduação, nunca houve uma pretensão de especialização nos estudos ligados à manualística. Não obstante, ao longo dos anos, tomamos tais análises como momento importante de nossos estudos e buscamos sempre avançar nas perspectivas adotadas, entendendo que as contribuições teóricas da educação no/ do campo são de suma relevância para tal feito.

\section{2 - METODOLOGIA EMPREGADA}

Esta é uma pesquisa qualitativa em educação, com foco em pesquisa bibliográfica e documental, que foi o caminho primeiro para a execução da análise de conteúdo de livro didático. Ademais, partimos do princípio de que o livro didático é um instrumento de ensino na escola, que, como instituição social, não raro é um dos principais centros de socialização da cultura no campo. Assim, ela pode tanto valorizar a identidade camponesa como rechaçá-la, reproduzir os modelos vigentes no meio urbano ou levantar e executar, junto com a comunidade escolar, ações e reivindicações que promovam as mudanças necessárias para o fortalecimento do campesinato, processo em que o livro didático é um elemento importante. Concordamos ainda com Lajolo (1996, p.4) ao pontuar que, embora o livro didático (...) 
"não seja o único material de que professores e alunos vão valer-se no processo de ensino e aprendizagem, ele pode ser decisivo para a qualidade do aprendizado resultante das atividades escolares".

Em primeiro lugar, fez-se necessário o procedimento com documentação indireta, como o levantamento e análise de fontes secundárias (bibliográficas) com localização das obras relacionadas ao objeto de estudo desta pesquisa, compilação do material bibliográfico e fichamento para posterior identificação das publicações relacionadas particularmente com o livro didático e sua aplicação no ensino de Geografia no Brasil. As teorias da educação do campo para se pensar a valorização da identidade territorial camponesa foram fundamentais também nesse momento.

Elencamos para nossa análise a coleção de livro didático - manual do professor - de Geografia intitulada Expedições Geográficas, de Melhem Adas e Sérgio Adas, versão adequada à Base Nacional Comum Curricular (BNCC). Essa coleção, voltada para o ensino fundamental II, vem sendo adotada nas escolas municipais do campo de Formosa, que recebem maior quantitativo de alunos. Nosso interesse pelo manual do professor reside nas proposituras pedagógicas direcionadas ao professor, que evidenciam mais claramente as perspectivas paradigmáticas que orientam a coleção e podem ser observadas nos encaminhamentos das abordagens didáticas dos conteúdos sugeridos ao professor, fato que não aparece no livro didático do alunado.

Posteriormente, partimos para a análise do livro. Para tanto utilizamos parâmetro de cunho geral, ligado à coleção em seu todo, e específico, compreendendo as análises pormenorizadas de cada volume da coleção. Os parâmetros de viés geral foram: apresentação geral dos volumes da coleção (capa, páginas, autor/autores, editora, ano de edição); editorial (qualidade do papel, estrutura hierarquizada; impressão, sumário, referências, legibilidade do texto e das figuras); ilustrações (legendas adequadas, escala, orientação, indicação de fontes e datas); organização da coleção (estrutura de organização do livro); perfil das atividades (tipo de atividade e possibilidades de estímulo ao desenvolvimento de competências e habilidades); categorias, conceitos e temas que fundamentaram as abordagens da coleção. Já para a análise específica de cada volume, os parâmetros foram: categorias e conceitos norteadores; termo utilizado para designar o campo; dimensão em que os autores enfatizaram o campo; formas de representar o campo; apresentação sucinta dos temas; caracterização do "campo"; caracterização do camponês; ênfase em determinadas dimensões (política, social, econômica, etc.) do campo; possibilidades para trabalhar com a identidade territorial camponesa.

Assim, apresentamos a seguir breves análises, entendendo que esta pesquisa pode ser constantemente aprofundada num processo dinâmico de reconfiguração das leituras. Além disso, como tomamos a educação no/do campo e a Geografia escolar como foco central da análise, portanto pensando nelas como mediadoras de culturas, e levando em conta seu caráter e sua importância social, torna-se ainda mais difícil afirmar que uma pesquisa que envolva tais temáticas se encerre com sua finalização. 


\section{3 - PERSPECTIVAS TEÓRICAS PARA SE PENSAR A IDENTIDADE TERRITO- RIAL CAMPONESA}

Entendemos identidade como a fonte de significado e experiência de um povo (CASTELLS, 2006, p. 22). No caso da identidade territorial, esse significado e essa experiência são constituídos por meio das relações construídas no território, cotidianamente marcadas por um poder que consolida um território material ou/e imaterial.

A categoria território, que está posta nesse conceito, nada mais é que um espaço onde ocorrem as relações de poder (RAFFESTIN, 1993). O território possui vários atributos, como a multidimensionalidade - política, social, econômica, etc. - e as escalaridades micro e macrodimensionais em que essas relações de poder podem se estabelecer, como a casa, o município, o estado, etc. (SOUZA, 1995), além de suas formas indissociáveis, que são a materialidade e a imaterialidade. É preciso notar, ademais, que as relações de poder não se limitam a um poder centrado apenas no Estado. O poder do Estado, principalmente político e administrativo, é relevante, mas não é o único.

Outro conceito relevante nesta pesquisa é o de camponês, que adotamos a partir do paradigma do "fim do fim" do campesinato, cujo principal objetivo é defender a existência desse sujeito que, segundo Fernandes (2004), se constitui a partir de sua resistência. Sobre isso, Ariovaldo Umbelino salientou que:

Sabe-se bem que a sobrevivência é o limite para a produção camponesa no campo, e não o lucro médio. No trabalho camponês, uma parte da produção agrícola entra no consumo direto do produtor, do camponês, como meio de subsistência imediata, e a outra parte, o excedente, sob a forma de mercadoria, é comercializada (OLIVEIRA, 2007, p.40).

De certo modo, esse autor apresentou algumas características de dimensão econômica para definir o campesinato brasileiro e, além disso, enquanto categoria social, podemos destacar características de cunho cultural, como o modo de vida do camponês, que se apresenta de diversas formas nas múltiplas escalas do espaço brasileiro.

É nesse contexto que entendemos a identidade territorial camponesa como aquela construída a partir de uma alusão ao território e ao sujeito. Ao compreendermos que o território é multidimensional, não podemos conferir a essa identidade só a relação com os elementos culturais que se dão no território, tampouco somente com a dimensão econômica: a identidade territorial camponesa se estabelece numa totalidade territorial que abarca ambas as dimensões. Ainda, de acordo com Fernandes e Molina,

Para garantir a identidade territorial, a autonomia e organização política é preciso pensar a realidade desde seu território, de sua comunidade, de seu município, de seu país, do mundo. Não se pensa o próprio território a partir do território do outro. Isso é alienação (FERNADNES E MOLINA, s/d. p.8). 
Assim, tomamos a ideia de que é justamente a forma como o camponês constrói suas relações no território, ou seja, a forma como ele vive que o diferencia do agricultor capitalista e que compõe a sua identidade territorial camponesa. Dentre os elementos culturais, além dos econômicos (produção agropecuária voltada para suprir primeiramente a família, mão de obra majoritariamente familiar, etc.) citados por Oliveira (2007), enfatizamos que a identidade do campesinato no Brasil atual é marcada por uma territorialização que se faz a partir da luta pela terra no período do acampamento, logo, por reunião, articulações, manifestações, passeatas, despejos, dificuldades e privações materiais nas moradias improvisadas em barracas de lona, mas também pela conquista da terra materializada no momento do assentamento e pelas relações de cooperação; o mutirão; a tradição e as reuniões festivas.

Percebe-se então que, na identidade territorial camponesa, o território não é valorizado ou marcado apenas pela dimensão econômica, pela capacidade de gerar capital, mas, acima de tudo, por ser espaço de vida marcado por hábitos, costumes e valores diferenciados daqueles dos valores atribuídos ao território dos produtores capitalistas.

Note-se que é no processo de constituição do modo de vida desse sujeito sobre o espaço que se dá a formação e a consolidação da identidade territorial camponesa. Essas e outras "potencialidades" precisam ser valorizadas no livro didático de Geografia, pois, conforme afirma Albuquerque (2011, p. 262), "quando os professores tomam o livro didático como guia de suas funções práticas, o livro didático torna-se um currículo”. Ademais, a LDB ainda garante, conforme o Art. 28.: "Na oferta da educação básica para a população rural, os sistemas de ensino promoverão as adaptações necessárias à sua adequação, às peculiaridades da vida rural e de cada região, especialmente: I - conteúdos curriculares e metodologias apropriadas às reais necessidades e interesses dos alunos da zona rural”.

São relevantes também as Diretrizes Operacionais para a Educação Básica nas Escolas do Campo, legalizadas na Resolução CNE/CEB nº 1, de 03 de abril de 2002, pois apresentam elementos importantes para refletir sobre os conteúdos de geografia no livro didático, principalmente no que diz respeito à perspectiva de valorização do campo como território de diversidades. Nessa resolução, destaca-se que:

Art. $5^{\circ}$ As propostas pedagógicas das escolas do campo, respeitadas as
diferenças e o direito à igualdade e cumprindo imediata e plenamente o
estabelecido nos artigos 23,26 e 28 da Lei 9.394 , de 1996 , contemplarão a
diversidade do campo em todos os seus aspectos: sociais, culturais, políticos,
econômicos, de gênero, geração e etnia (BRASIL, MEC.DIRETRIZES
OPERACIONAIS PARA A EDUCAÇÃO BÁSICA NAS ESCOLAS DO
CAMPO. 2002, p. 38).

Nesse contexto, os conteúdos geográficos têm papel fundante, pois a Geografia não é apenas uma disciplina de síntese, mas é um componente cuja relação espaço/tempo/ território permite pensar, analisar e apontar os elementos que compõem a identidade territorial camponesa. É nesse sentido que os livros didáticos são instrumentos importantes para se materializar o ensino-aprendizagem numa perspectiva de valoração das diversidades do território do camponês. 
Por fim, apresentamos os resultados da análise, entendendo que a pesquisa qualitativa em educação, independente do momento, é desafiadora por estar atrelada a uma instituição em constante movimento.

\section{4 - OS LIVROS DIDÁTICOS DE GEOGRAFIA: PERSPECTIVAS TEÓRICAS E METODOLÓGICAS NA VALORIZAÇÃO DA IDENTIDADE TERRITORIAL CAMPONESA}

Os livros didáticos no Brasil vêm se consubstanciando a partir do currículo mínimo adotado no ensino básico, de modo que vêm sendo orientados a partir dos currículos oficiais como os Parâmetros Nacionais Curriculares (PCNs), instituídos na década de 1990, as reorientações curriculares estaduais, e, mais recente, as Bases Nacionais Comuns Curriculares (BNCC). Ademais, o livro didático vem se concretizando como um território em disputa, visto que, a cada mudança de governo, implementa-se uma reorientação ou complementação curricular.

Nesse processo, a escolha do livro didático é acima de tudo um ato político. É preciso estar atento aos discursos implícitos nesse material escolar, pois este é crucial para a execução do trabalho docente, dado o seu status de instrumento de aprendizagem para o aluno, de suma importância para o andamento do trabalho docente. Essa escolha precisa estar atrelada aos objetivos de ensino, os quais, por sua vez, precisam ser adequados à realidade do alunado, do professor, da escola e, acima de tudo, ao projeto político pedagógico da escola.

Ademais, em se tratando de um livro utilizado em escolas que recebem alunos do campo, é preciso observar que existe uma política nacional de educação do campo, então é necessário analisar os conteúdos na perspectiva de sua adequação ao marco legal que reconhece a importância do ensino com foco na valorização e diversidade do/no espaço rural. Nesse contexto, é preciso observar se o debate sobre o espaço rural é totalizante, se valoriza as singularidades do espaço agrário e agrícola, e tomar cuidado com o discurso que supervaloriza determinadas técnicas e produtos agrícolas, assim como os debates duais da geografia que colocam a produção camponesa como arcaica e atrasada, e a agricultura moderna como o principal modelo de produção para o campo.

Outro elemento a ser observado é a dimensão que recebe destaque nos conteúdos ligados ao campo, pois esta não pode estar alheia às diretrizes operacionais formuladas para a educação básica das escolas do campo. É comum nos livros didáticos uma ênfase à dimensão econômica em detrimento da social. Essa primeira apresenta uma geografia dos números, quantificando produção e espacializando fenômenos no campo a partir da Geografia agrícola e quantitativa. Enfim, é preciso tomar cuidado com livros que reproduzem o paradigma do capitalismo agrário ${ }^{2}$, que enfatiza o campo apenas como produtor de commodities, esquecendo

2 O capitalismo agrário, segundo Fernandes (2004), surgiu na década de 1990, anunciando o fim do campesinato. Nesse paradigma, a superação do campesinato "pode acontecer desde que o desenvolvimento do capitalismo atinja um determinado estágio, em que as relações sejam determinadas por estruturas nacionais de mercado e por um controle rigoroso desse processo pelo Estado.” (ABRAMOVAY, 1992, p. 249). 
que o mesmo é espaço de produção e reprodução de vida também, cujas dimensões totais precisam estar presentes nos livros didáticos.

A temática campo e cidade também deve ser analisada, visto que, comumente, os livros apresentam a cidade como espaço moderno sobrepondo-se ao campo, considerado atrasado. Estes e outros critérios devem ser observados para a escolha de um livro voltado para alunos do campo. Ainda, concordamos que:

Os livros didáticos podem e devem desempenhar: a) um papel pedagógico, assegurando uma concepção eproposta pedagógica adequadaàs características dos sujeitos do campo e a veiculação de conceitos e informações, mantendo coerência da sua opção metodológica e; b) um papel social, de defesa do campo como um espaço de cultura, produção e conhecimento, contribuindo para a construção de um projeto de desenvolvimento sustentável do campo. (MEC. PNLD CAMPO, 216, p41)

Quanto à análise dos livros didáticos, como já destacado, nesse primeiro momento focamos os quatro volumes de livros didáticos da coleção Expedições Geográfica (manual do professor), de autoria de Melhem Adas e Sergio Adas, publicados pela editora Moderna.

\section{5 - ASPECTOS GERAIS SOBRE A COLEÇÃO DE LIVRO DIDÁTICO}

Observando a diagramação da coleção aqui analisada, podemos destacar que ela é constituída de capa brochura, organizada em quatro volumes, cada um com oito unidades temáticas que, por sua vez, contém quatro percursos. O total de páginas varia de 248 a 288 , dependendo do volume. A qualidade do papel é razoável, visto que é possível ver o outro lado da folha. O tamanho de letra está legível, mas com muitos textos e espaço simples entre as linhas. As figuras atravessam praticamente todos os textos.

Em se tratando de sua estrutura, a coleção dos volumes se organiza por meio de elemento chamado de abertura de unidade, além do recurso intitulado percurso, que apresenta o conteúdo e está presente em praticamente todos os capítulos. Existem ainda outros aportes distribuídos ao longo do livro, como as estações que apresentam conteúdos complementares por meio de textos e sites: estação cidadania, estação socioambiental, estação ciências e estação história. Observa-se ainda os infográficos, que aparecem de forma esporádica para apresentar os conteúdos por meio de ilustrações. Há, ainda, a mochila de ferramentas, que sugere técnicas de estudo, as atividades, e as rotas e encontros com trabalho ligados à dimensão cultural do conteúdo.

Para encerrar parte das unidades, os livros possuem ainda tópicos denominados desembarque em outras linguagens e caminhos digitais, que trabalham respectivamente com abordagens interdisciplinares e a cultura digital. De modo esporádico, também aparecem as seções laterais que sugerem livros, vídeos, sites e propõem atividades articuladoras. É importante destacar que esses recursos, com exceção do percurso, não estão presentes em todas as unidades dos volumes da coleção. 
Tendo tudo isso em vista, essa obra pode ser designada como um livro de terceira geração, como classifica Tonini (2011) para se referir a livros que utilizam diversas formas textuais. Ademais, podemos afirmar que esses livros didáticos vêm apresentando maior possibilidade de interação com o alunado, embora seja claro que isso depende também do professor, uma vez que esses recursos precisam ser explorados por eles.

Observamos também que há um direcionamento didático sobre os conteúdos pontuando o que deve ser aprofundado, o que pode auxiliar, mas por outro lado também pode contribuir ainda mais para que o professor se prenda ao livro, esquecendo as especificidades da escola e as singularidades de cada sala de aula, deixando de lado, ainda, os objetivos de ensino propostos. Um exemplo disso ocorre na página 213 do livro destinado ao $6^{\circ}$ ano, que apresenta sugestão de análise da estrutura fundiária para trabalhar o conteúdo de concentração fundiária.

As ilustrações auxiliam na leitura e compreensão de texto. Estas possuem fonte e data, além de todos os elementos cartográficos necessários, como legenda, orientação e escala. Já quanto às atividades ligadas ao conteúdo sobre o espaço rural, percebemos que, embora haja a geografia agrária e uma tentativa de aproximar a mesma à realidade do aluno, há uma predominância de atividades ligadas à geografia agrícola, cuja dimensão enfatizada é a econômica.

\section{6 - ANÁLISES DE CUNHO MAIS ESPECÍFICO DOS VOLUMES DA COLEÇÃO: OS CONTEÚDOS}

Observando os conteúdos ligados ao campo, podemos afirmar que, no caso do volume do $6^{\circ}$ ano, essa temática está na unidade 7 , intitulada de agropecuária, com um total de 21 páginas e os seguintes temas gerais: a agricultura; agricultura e condições naturais; geografia agrícola do Brasil: sistemas de produção e uso da terra; a agricultura e a disseminação de plantas; a pecuária.

Já no volume do $7^{\circ}$ ano, os conteúdos ligados ao espaço rural estão diluídos em algumas unidades, como a 6, 7 e 8, em um total de sete páginas. São denominados: a cafeicultura e a produção de espaços geográficos no Sudeste (unidade 6), com subtítulos: a expansão da cafeicultura em direção ao interior de São Paulo, com subdivisões desse conteúdo em ferrovias, cafeicultura e produção de espaços geográficos; cafeicultura e a migração estrangeira (Unidade 6); futuro da agricultura depende dos cuidados com o solo (unidade 7); a expansão da fronteira agrícola no Centro-oeste (unidade 8).

No volume do $8^{\circ}$ ano, o conteúdo que nos interessa também está diluído em algumas unidades, como a 4, 5 e 6, em um total de 10 páginas. São intitulados: o maior produtor e o maior consumidor, um gigante na agropecuária; agropecuária no México, na Argentina e no Brasil. Esse percurso é subdivido em outros temas ligados ao campo (p. 172-175). Dentro do percurso 22, há algumas subdivisões, como: a concentração e questão da terra na América Latina (p. 191), o caso do chile: agricultura de alta especialização e o cobre (p.193) e, por fim, América Central: economias com base agropecuária, que abrange todo o percurso 23 da página 208 a 213. 
Por fim, no volume do $9^{\circ}$ ano, os conteúdos ligados ao espaço rural estão concentrados apenas na unidade 2, no percurso 5 situado na página 50. Podemos ainda encontrar essa mesma natureza de conteúdos abrindo o percurso 6 (nas páginas 52 a 57), intituladas de: transformação da produção agropecuária e urbanização. Sociedade Urbano-industrial e a importância da agropecuária com subtítulos: participação agropecuária no comércio mundial; as commodities; commodities agropecuária, uso da terra e indústria de alimentos; desigualdade mundial de acesso a alimentos; causa da insegurança alimentar; agricultura urbana; direito humano à alimentação adequada e soberania alimentar.

\section{1 - O CAMPO NO LIVRO DIDÁTICO}

Pensar a categoria e a perspectiva em que os livros didáticos vêm se apresentando para designar o campo é um exercício importante, visto que precisamos entender esse território a partir da sua totalidade, da sua diversidade, multiescalaridade e multidimensionalidade, de modo que o termo empregado deve abarcar teoricamente todos esses elementos. O significado desse território, constituído no livro didático, precisa ser também uma das preocupações dos professores, pois é necessário pensar o campo como um território também a partir das multiterritorialidades e possibilidades para a construção das relações sociais.

No senso comum, os termos: rural, campo, agrário e agrícola são tomados por sinônimos, mas sabemos que eles são divergentes. Trata-se de concepções e formas distintas de ver esse território que têm sido levantadas. Assim, concordamos com Andrade (1995) que ao distinguir a Geografia Agrária da Geografia Agrícola apresenta perspectiva distintas das mesmas e nos ajuda a entender os termos supracitados:

As preocupações sociais, integradas à problemática da estrutura agrária e das relações de trabalho no meio rural, contribuíram para caracterizar uma geografia agrária que se distinguiria do que se chamaria de geografia agrícola ou da agricultura, onde a preocupação maior se ligava aos problemas de produção, de mercado, de produtividade e de rentabilidade (ANDRADE, M. C. de., 1995, p.10).

A Geografia Rural, conforme Andrade (1995) tinha uma preocupação maior com a totalidade do conhecimento abarcando a dimensão econômica e social. A distinção dessas geografias contribui para a diferenciação dos termos: agrário, agrícola e rural. Assim, entendemos que o termo agrícola está vinculado a produtividade, a produção, a rentabilidade, e a outras perspectivas mais voltadas para a dimensão econômica no meio rural. Já, o termo agrário está vinculado a dimensão social nesse espaço supracitado. O termo rural abarca os estudos em sua totalidade dimensionais.

A educação do campo retoma o conceito de campo para o movimento entendendo sua a importância, assim como explicam Arroyo, Caldart e Molina (2004, p. 25): "Decidimos utilizar a expressão campo e não a mais usual meio rural, com o objetivo de incluir no processo da conferência uma reflexão sobre o sentido atual do trabalho camponês e das lutas sociais e culturais dos grupos que hoje tentam garantir a sobrevivência deste trabalho". 
Então, ao analisar os termos utilizados para designar o campo nos livros didáticos, percebemos que, no volume destinado ao $6^{\circ}$ ano, embora a palavra campo apareça uma vez na página 212, não há mais referência a qualquer termo para designar campo, ou espaço rural, dando a impressão de que os fenômenos não acontecem no espaço, mas que estão soltos, sendo muitas vezes representados por dados. Já no volume do $7^{\circ}$ ano, não há registro de nenhum termo para referir o campo. No volume do $8^{\circ}$ ano, a palavra campo aparece uma única vez, para falar em modernização do campo (p.130). E, por fim, no volume do $9^{\circ}$ ano, campo é utilizado para se levantar questões (p. 52) e para falar das relações no campo (p.54). Assim, percebemos uma homogeneidade na abordagem do termo, pois a única palavra que aparece é campo, no entanto as referências à mesma são escassas nos volumes.

Analisamos também a forma como o campo é representado, observando qual geografia predominava. Nos volumes do $6^{\circ}$ e $7^{\circ}$ anos, o campo é majoritariamente caracterizado por meio da geografia agrícola, ressaltando técnicas agrícolas, agricultura, tipos de agricultura, sistemas de produção e uso da terra e pecuária, apontando as formas de criação de gado. $\mathrm{O}$ autor apresenta de forma breve e tímida algumas críticas sobre as consequências do uso de agrotóxicos. Ainda, em conformação resumida, ocupando praticamente uma página e meia, apresenta um debate ligado à geografia agrária, pontuando a questão da terra no Brasil, com ênfase para concentração fundiária e movimento dos trabalhadores rurais no volume do $6^{\circ}$ ano (p. 212 a 213). Vale ressaltar que, neste, há breves passagens (p.212) sobre o trabalho análogo à escravidão no campo e os problemas ambientais ligados à produção de cana de açúcar, tudo isso em apenas cinco parágrafos, ocupando um quarto da página. Isto é preocupante, pois esse tema é de suma relevância nos debates ligados à questão agrária e marca a identidade de muitos camponeses no Brasil.

É interessante destacar que há uma proposição (volume do $6^{\circ}$ ano) ao aluno para que ele pontue se há em sua região movimentos dos trabalhadores rurais sem terra. Nesse momento, o professor pode explorar esse tema, aprofundando a geografia agrária tão escassa. Chama a atenção também o fato de o autor, não obstante tenha discutido pouco os temas da questão agrária, sugira documentários que possibilitam aprofundar também esse tema nas sugestões de filmes. Certamente, o professor terá que complementar o conteúdo com textos visando a trabalhar as categorias da Geografia agrária que abordam a perspectiva da luta pela terra no Brasil.

Já nos volumes dos $8^{\circ}$ e $9^{\circ}$ anos, o campo é caracterizado majoritariamente pela geografia agrícola $\mathrm{E}$, de forma tímida, aparece a concentração e questão da terra na América Latina no volume do $8^{\circ}$ ano (p. 191 e 192). Este último tema é relevante, pois vem sendo constituído a partir da luta pela terra para os alunos camponeses no Brasil. Então, caberá ao professor valer-se desse momento para destacar os elementos ligados ao processo de territorialização desses camponeses. Levantar os elementos que caracterizam essa territorialização é importante para a valorização da identidade territorial camponesa advinda da luta pela terra.

Ao fim, percebe-se que, nessa coleção, o que predomina nos conteúdos ligados ao campo é a geografia agrícola, cujas abordagens fazem parte dos discursos da geografia nas primeiras décadas do século XX. Pautada em um discurso geoeconômico, era muito comum 
a caracterização das paisagens a partir da produção agropecuária, e percebe-se que, como a base da economia do Brasil no início do século XX ainda era agrária, esse tema polarizava os estudos de Geografia naquele momento. Essa tendência ainda está muito presente nos discursos dos livros didáticos aqui analisados, e isso é preocupante, pois limita as análises e centraliza o debate ligado ao campo. Ao enfatizar essa Geografia, os problemas sociais no campo são ignorados ou pouco abordados.

\section{2 - O CAMPONÊS NO LIVRO DIDÁTICO}

Outro aspecto analisado foi como o camponês é caracterizado em cada módulo. O termo camponês vem sendo trabalhado dentro da perspectiva do paradigma da questão agrária, e possui especificidades teóricas e metodológicas distintas do termo agricultor familiar. Pensar o campo a partir dessa categoria é reconhecer no termo camponês seu caráter de resistência, sua existência a partir da terra como espaço de produção de vida. No contexto de análise do livro didático adotado no campo, é de suma importância observar quais são os sujeitos que estão sendo representados, até porque, no Brasil, as escolas no campo recebem majoritariamente alunos camponeses. Os filhos dos grandes produtores agrícolas estudam geralmente em escolas particulares na cidade. Se o processo de constituição de identidades é acima de tudo simbólico, como o alunado camponês reconhecerá as suas identidades a partir da ausência de si mesmos nos livros didáticos?

No volume do $6^{\circ}$ ano, o termo camponês não é utilizado, mas sim o termo agricultor/agricultores, quase sempre acompanhado por fotos. Quando o termo agricultor aparece, é para demonstrar a produção agrícola. Logo, o "agricultor" aparece colhendo ou plantando algum produto agrícola. Outro termo utilizado é lavrador, também para referir-se à plantação (p.208). Aparecem também as expressões pequeno proprietário e pequenos arrendatários, sujeitos que, segundo o autor, geralmente utilizam mão de obra familiar para sua produção (p.211). Na página 213, o autor faz menção às ligas camponesas, mas não explica o que foram ou o seu papel na luta pela terra.

No volume do $7^{\circ}$ ano, não aparece menção ao camponês, há apenas uma foto com trabalhadores rurais. É um campo sem sujeito. No volume do $8^{\circ}$ ano, por sua vez, há duas menções ao camponês: quando há sugestão de filme sobre o Zapata, o autor afirma que o mesmo era um camponês, e na página 192 a categoria é mencionada para destacar uma figura com manifestação pela posse da terra. Na mesma página, camponeses e pequenos proprietários são referidos sem que se faça diferenciação desses conceitos, o que pode confundir o alunado. E, por fim, no volume do $9^{\circ}$ ano, nas partes em que há aprofundamento sobre os conteúdos ligados ao campo, o sujeito camponês não aparece, apenas populações que saem do campo (p.50). É grave que todas essas categorias sejam utilizadas sem fazer a devida distinção, visto que isso pode confundir os alunos e dificultar as conceituações. A pouca referência ao camponês também é preocupante, uma vez que, como já apontamos, o aluno não reconhece a si mesmo no livro didático, logo não reconhece elementos que marcam sua identidade territorial. 


\section{3 - AS IMAGENS NOS LIVROS DIDÁTICOS}

As imagens contidas no livro didático não são simples aportes para o texto. Nesse sentido, concordamos com Tonini (2003, p35), que pontua que a imagem é "uma máquina óptica poderosa para veicular significados". Ler de forma crítica as figuras inseridas nos livros didáticos adotados pelas escolas no campo é exercício fundamental no processo de desconstrução das mesmas, observando como e para quem elas foram construídas e qual paradigma elas de fato representam. As visões de mundo embutidas nas imagens podem moldar subjetividades, são tomadas muitas vezes como verdades sem qualquer questionamento mais crítico. O professor das escolas no campo precisa, portanto, ficar atento aos paradigmas que predominam nas figuras inseridas nos livros didáticos, visto que "há uma tendência dominante em nosso país, marcado por exclusão e desigualdades, de considerar a maioria da população que vive no campo como parte atrasada e fora de lugar no almejado projeto de modernidade" (FERNANDES; CERIOL; CALDART, 1998, p. 4).

Assim, outra análise de suma importância aqui realizada foi como as figuras, ilustrações e mapas retratam o campo, procurando observar quais sujeitos ou situações são mais representados nelas. No volume do $6^{\circ}$ ano, majoritariamente, as figuras ligadas ao campo retratam a Geografia agrícola, pontuando a produção agropecuária em praticamente todas as fotos. Mesmo quando o camponês ou o trabalhador rural aparece, ele está colhendo ou plantando algum produto agrícola. Os mapas também só retratam a produção agrícola, área irrigada e uso e ocupação do solo. Apenas uma tabela traz a estrutura fundiária (p. 213) retratando a questão agrária no Brasil. As atividades da página 219 apresentam ainda duas charges: uma sobre latifúndio e outra que faz um trocadilho com as cidades, pontuando "inchadas paradas", fazendo apologia aos problemas urbanos advindos do êxodo rural.

No volume do $7^{\circ}$ ano, existe um mapa da cultura do café ao longo das vias férreas de 1946 em São Paulo e outra foto com trabalhadores na colheita de café (p.201), além de fotos retratando impactos ambientais causados pela pecuária no Rio Grande do Sul e com manifestação a favor da proteção dos solos. Há também charges sobre o mesmo assunto. Enfim, ora é a produção agrícola que toma a centralidade do debate, ora são os impactos ambientais.

Já no volume do $8^{\circ}$ ano, verificamos: mapa com cinturões agropecuários; gráfico com quantidade e área média da propriedade; fotos de trabalhador arando a terra; mapa com agropecuária na Argentina; fotos da colheita mecanizada e criação de gado na Argentina; gráfico e mapas com produção de soja no Brasil e, por fim, fotos de passeata pela reforma agrária no Paraguai e manifestação por terra no Chile.

Por fim, no $9^{\circ}$ ano, os mapas, gráficos e tabelas aparecem para espacializar a produção agropecuária e as commodities; há uma fotografia da produção de soja e de uma colheitadeira em plantação de soja, além de uma foto de uma horta urbana. O grande produtor capitalista é o principal representado nessas figuras.

De modo geral, as ilustrações, mapas e tabelas inseridas em cada volume estão sendo utilizadas em grande porcentagem para ilustrar ou especializar a geografia agrícola. Nesse contexto, o professor deve atentar-se ao fato de que é preciso: 
Examinar a imagem veiculada nos livros didáticos de Geografia como produtora de significados, que utiliza diversas estratégias implicadas em relações de poder para tecer uma malha privilegiada para determinados conhecimentos, é entender que o significado não existe no mundo, não é encontrado como elemento da natureza, como algo que está vagando, o qual basta pegarmos para colocar sobre as coisas, sobre os objetos que está (TONINI, 2011, p. 153).

Nesse sentido, caberá ao professor questionar o significado dessas figuras e desconstruir o significado perverso que está por trás desses textos visuais. Esse excesso de imagens ligadas à geografia agrícola com foco no paradigma do capitalismo agrário exclui o modo de vida campesino.

\section{4 - AS DIMENSÕES REPRESENTADAS NOS LIVROS DIDÁTICOS}

Analisamos também as dimensões (política, social, econômica, etc.) predominantes nos volumes da coleção. No volume do $6^{\circ}$ ano, praticamente todo o conteúdo ligado ao campo enfatiza a dimensão econômica, e o social é retratado de forma breve, por meio de problemas ligados à questão da terra no Brasil, com ênfase em concentração fundiária e movimento dos trabalhadores rurais (p. 212 e 213). Quando o camponês é apresentado, destaca-se a produção na qual ele está envolvido, seja colhendo ou plantando.

No volume do $7^{\circ}$ ano, a dimensão econômica também predomina, e a social aparece com ênfase na agricultura e em problemas ambientais. No livro do $8^{\circ}$ ano, a mesma dimensão é enfatizada, enquanto o social é abordado mais superficialmente, por meio de problemas ligados à questão da terra na América Latina, com ênfase em concentração fundiária e movimento dos trabalhadores rurais (p.191). E, no volume do $9^{\circ}$ ano, há a mesma ênfase na dimensão econômica, por meio das commodities e pela participação da agropecuária no comércio mundial e a agricultura de precisão. Existe nesse volume um pequeno destaque para a dimensão social quando aponta a insegurança alimentar e a soberania alimentar.

Devemos observar que o território do camponês é construído por e a partir de práticas sociais imbuídas de disputas materiais e imateriais constantes e, nesse processo, as várias dimensões fazem parte da dinâmica que forma esse território. Nesse contexto, as Diretrizes operacionais para a educação básica nas escolas do campo destacam que:

Art. $5^{\circ}$ As propostas pedagógicas das escolas do campo, respeitadas as diferenças e o direito à igualdade e cumprindo imediata e plenamente o estabelecido nos artigos 23, 26 e 28 da Lei 9.394, de 1996, contemplarão a diversidade do campo em todos os seus aspectos: sociais, culturais, políticos, econômicos, de gênero, geração e etnia (DIRETRIZES OPERACIONAIS PARA A EDUCAÇÃO BÁSICA NAS ESCOLAS DO CAMPO. 2002, p. 38).

Assim, ao abordar apenas a dimensão econômica, o livro didático prioriza um discurso que não revela esse território em sua totalidade e não contribui para um dos principais objetivos da geografia, que é entender sobretudo a dinâmica socioespacial e, a partir disso, questionar e, se necessário, instigar os sujeitos para a transformação da realidade. 


\section{5 - PERSPECTIVAS PARA PENSAR A IDENTIDADE TERRITORIAL CAMPONESA}

Por fim, avaliamos também se os volumes abrem a possibilidade para a valorização da identidade territorial camponesa. Concluímos que, em função da ênfase na Geografia agrícola e na dimensão econômica e pela predominância de imagens que retratam o paradigma do capitalismo agrário, essa possibilidade é escassa. Desse modo, caberá ao professor descontruir o discurso presente no livro e, por vezes, complementar o conteúdo com material didático que problematize as questões e apresente o campo como espaço de reprodução de vida, como lócus de vida também do camponês. Afinal, como pontua Tonini (2003, p36), o livro didático "atua, como macrodiscurso, por expressar as visões e os significados do projeto dominante, ajudando a reforçá-las, a dar-lhes acolhida e, como microtexto, como prática de significação em sala de aula”.

\section{7 - CONSIDERAÇÕES FINAIS}

A partir das análises dos livros didáticos apresentadas nesse artigo, ficou evidente que os mesmos, na medida em que sejam tomados de forma fiel pelos professores de Geografia em suas práxis, vêm concorrendo para uma não valorização da identidade territorial camponesa.

Nessa coleção, o campo foi representado majoritariamente por meio de abordagens ligadas à agricultura, o que é preocupante, pois, como já pontuou Ferreira (2001), os estudos geográficos que priorizavam a agricultura se fizeram mais presentes nas décadas de 1930 a 1940, período em que o papel prioritário desempenhado pela atividade agrícola colocou-a como temática principal dos trabalhos. Entretanto, percebe-se que essa abordagem focava sobretudo a geografia agrícola em detrimento de uma abordagem mais totalizante, em que os aspectos sociais e culturais também poderiam ser destacados.

Percebe-se ainda que, nos volumes, houve uma preocupação em adotar um único termo específico para designar o campo, entretanto, a sua representação é escassa, e não houve preocupação em definir o significado dos diversos termos adotados (camponês, produtor rural, trabalhador rural). Ainda, foi priorizada uma abordagem compartimentada dos conteúdos, sendo que as análises ligadas ao campo estão concentradas em um ou dois capítulos dos volumes. $\mathrm{O}$ volume que tem mais conteúdos ligados ao campo é o do $6^{\circ}$ ano.

O estudo da geografia agrícola é priorizado em todos os livros analisados, entretanto, percebe-se maior cuidado com a geografia agrária nos volumes dos $6^{\circ}$ e $8^{\circ}$ anos. É pouca a preocupação com uma abordagem que permita ao aluno dialogar, pensar e construir sua própria criticidade acerca da realidade sociocultural de seu território, cabendo ao professor a preocupação com uma práxis que permita aproximar o conteúdo à realidade campesina. Percebemos, nos conteúdos, destaque para a produção agropecuária e não para a vida no campo. Tal abordagem explicita a valorização do campo como um espaço de produção agropecuária, desmerecendo a sua importância como território de vida, com seus hábitos, costumes, valores, etc. 
Os volumes $\left(6^{\circ}\right.$ e $8^{\circ}$ ano $)$ mencionam a reforma agrária em poucas páginas. Há que se ressaltar a importância ímpar desse tema para o estudo da Geografia, com a eleição da categoria camponês. Primeiro, porque tal abordagem é recente nos livros didáticos de geografia e, segundo, por conta da importância desse debate para a promoção de equidade social. Quando os autores trabalham com a categoria camponês, eles reconhecem a sua existência e resistência no meio capitalista, entretanto, ela aparece pouco. Também, considerando que alunos camponeses podem ser assentados, é de suma importância uma abordagem de cunho crítico, que reconheça a importância da reforma agrária no Brasil, na valorização da identidade territorial camponesa.

Por fim, cabe ressaltar que, apesar das fragilidades encontradas nos livros de geografia, estes são muitas vezes o principal instrumento que auxilia na aprendizagem. É na práxis docente que essas lacunas serão suprimidas, com métodos e metodologias voltadas ao ensino de geografia que valorize o cotidiano da comunidade campesina. Porém, para isso, o professor precisa muitas vezes reconhecer as fragilidades desse material didático e, depois, desconstruí-lo e reconstruí-lo, processo em que as teorias da educação do campo podem auxiliar, especialmente para uma leitura crítica desse material didático. 


\section{8 - REFERÊNCIAS}

ABRAMOVAY, Ricardo. Paradigmas do capitalismo agrário em questão. Campinas: Hucitec/Anpocs/Editora da Unicamp, 1992.

ANDRADE, M. C. de. Geografia rural: questões teórico-metodologicas e técnicas In:

Anais do XII Encontro Nacional de Geografia Agrária. Vol. 1, AGETEO - Rio Claro. 1995. p. 3-. 14. (Mesa redonda).

ARROYO, M. CALDART, R. S. MOLINA, M. C. Por uma educação do campo. Petrópolis : Editora vozes. 2004.

ALBUQUERQUE, M. A. M de. In:TONINI, I. M. et. al. O ensino da Geografia e suas composições curriculares. Porto Alegre: UFRGS. 2011. p. 155-168.

BRASIL. Lei de Diretrizes e Bases da Educação Nacional, LDB. 9394/1996.

BRASIL, Ministério da Educação. Diretrizes Operacionais para a Educação Básica nas Escolas do Campo - RESOLUÇÃO CNE/CEB N. 1, DE 03 DE ABRIL DE 2002.

BRASIL. MEC. Edital de convocação para o processo de inscrição e avaliação de obras didáticas para o programa nacional do livro didático do campo. 2016.<Disponível em: https://www.fnde.gov.br/index.php/programas/programas-do-livro/consultas/editais-programas-livro/item/5373-edital-pnld-campo-2016 > . Acesso em jan. de 2020.

CASTELLS, Manuel. O poder da identidade. Tradução Klauss Brandini Gerhardt. 5.ed. São Paulo: Paz e Terra, 1999.

FERNANDES, B, M. Delimitação Conceitual de campesinato. 2004. (texto não publicado) 5 páginas.

FERNADES, B. M. MOLINA, M. O campo da educação do campo. Disponível em: $<$ http:// www2.fct.unesp.br/nera/publicacoes/ArtigoMonicaBernardoEC5.pdf $>$. Acesso em 25 de abril de 2012.

FERnANDES, B. M. CERIOLI, P. R. CALDART, R. S. Conferência Nacional Por uma educação do campo. Texto Base. Brasília. 1998. Disponível em: . Acesso em: 21 nov. 2011.

FERREIRA, D. A. O. Geografia agrária no Brasil: conceituação e periodização. Terra Livre, n. 16, São Paulo, 2001, p. 39-70.

OLIVEIRA, A. U. de. Modo de produção capitalista, agricultura e reforma agrária. São Paulo: FFLCH/Labur Edições. 2007. Disponível em:< http://xa.yimg.com/kq/ groups/17929366/910294454/name/livro_aviovaldo.pdf>. Acesso em: 15 out. 2010.

RAFFESTIN, C. O que é território? In: por uma geografia do poder. SP: Ática, 1993. p. 143-185. 
SOUZA, M. J. L. O território: sobre espaço e poder, autonomia e desenvolvimento. In:. CASTRO, I. E de, GOMES, P. C da C. CORREAA, R. L. (Orgs). Geografia: conceitos e temas. 6.ed. Rio de Janeiro: Bertrand, 1995. p. 77-116.

TONINI, I. M. Livro didático: textualidade em rede ?. In:TONINI, I. M. et. al. O ensino da Geografia e suas composições curriculares. Porto Alegre: URGS. 2011.

Imagens nos livros didáticos de geografia: seus ensinamentos, sua pedagogia... Mercator - Revista de Geografia da UFC, ano 02, número 04, 2003. Disponível em: $<$ http:// www.mercator.ufc.br/mercator/article/view/148 >. Aceso em janeiro de 2019. 